\title{
An Empirical Relationship between Agriculture Investment and Economic Growth in North Macedonia: An ARDL Analysis
}

\author{
Nikolche Jankulovski ${ }^{1}$, Biljana Angelova ${ }^{2}$, Meri Boshkoska ${ }^{1}$ \\ ${ }^{1}$ University "St. Kliment Ohridski”, Bitola, N. Macedonia \\ ${ }^{2}$ University "Ss. Cyril and Methodius", Skopje, N. Macedonia
}

\begin{abstract}
The main aim of this paper is to find the relationship between agriculture investment and the growth of the gross domestic product in North Macedonia. We collected the yearly secondary time series data between the periods 1991 to 2020 . We run the ARDL co-integration test to check the long-run as well as the short-run relationship between dependent and independent variables. We found a positive and significant relationship between agriculture valueadded and the growth of the GDP in the long run. The agricultural land has a positive relationship with the growth of the GDP in the long run but negatively correlated in the short run. Last, both variables agricultural methane emissions and inflation are negatively correlated with the growth of the gross domestic product in both the long and the short run.
\end{abstract}

Keywords - GDP, agricultural value-added, Unit Root, Co-integration, Causality.

\section{Introduction}

Agriculture has changed over the past thirty years. The result has nearly doubled in agriculture production, which is driven in part by the fastest

DOI: $10.18421 /$ TEM103-60

https://doi.org/10.18421/TEM103-60

Corresponding author: Nikolche Jankulovski, Associate Professor, ul.Partizanska bb, Bitola, N. Macedonia.

Email: nikolce.jankulovski@uklo.edu.mk

Received: 14 June 2021.

Revised: 10 August 2021.

Accepted: 16 August 2021.

Published: 27 August 2021.

(c) BY-NC-ND (C) 2021 Nikolche Jankulovski, Biljana Angelova \& Meri Boshkoska; published by UIKTEN. This work is licensed under the Creative Commons AttributionNonCommercial-NoDerivs 4.0 License.

The article is published with Open Access at www.temjournal.com growing economy of the developing world and in part by change in developed countries. [1]

Above all else, there has been an unprecedented change in agricultural technology around the world.

Improving agricultural productivity capability in developing countries through increased productivity is a key policy objective where agriculture represents an important sector of the economy [5]. The agricultural sector provides direct and indirect livelihoods to a large proportion of the population of all developing countries, especially in rural areas, where poverty is most prevalent. Thus, the growing agricultural sector contributes to overall growth and poverty reduction [3].

Within food and agricultural growth, emphasis is placed on the expansion of arable land expansion in many countries due to a lack of suitable land or due to environmental needs [9]. In addition, the difference between the practical and technological yields of many crops means that there is great potential for increasing food and agricultural production through improved productivity, or no other technological advances [10].

According to Schultz [13], development dictates a decline in the role of agriculture. At first it was very dominant, eventually only a small portion of the total product, work and income were included. Khan [6], suggested that the successful adaptation to the changing role of agriculture not only sets the pace and pattern of development as a whole, but also the complexity of the problems that rural people face in the development process.

Agricultural development is necessary for two reasons, as a source of industrial and food resources, respectively and as a means of achieving the goals of employment-driven economic growth, poverty eradication and independence. Sustainable agricultural growth, therefore, has been a key component for many countries, at the same time increasing food accessibility and food security [8]. Much effort has been put into trying to increase productivity in agriculture and calls for more investment in agricultural science and technology, 
especially in Africa [7]. The reasons for this become apparent when one looks at product growth in developing countries. In many regions, significant progress has been made in increasing the land and productivity of the workforce in terms of units of product value [2].

People in developing countries who depend on agriculture for their livelihood are often poorer than those who work in other sectors of the economy. In general, many people living in rural areas [4]. Globally, the level of poverty has declined steadily, which is the most significant achievement of economic growth.

The two main sources of agricultural growth during the distribution of agriculture technology in the region have been the expansion of agricultural areas and the replacement of traditional and modern varieties [11]. However, over time the chances of increasing the area of sustainable farming decrease or almost disappear as the region has poor soil due to high human pressure. In addition, the demand for agricultural land is growing steadily. For example, it is estimated that in Bangladesh, every year $1 \%$ of the country's agricultural land is transferred to nonagricultural purposes [12].

The main aim of this study is to estimate the impact of agriculture on the growth of gross domestic product in North Macedonia. We collected the data for different independent variables from which most of related with agriculture production.

\section{Material and Methods}

The research objectives of this study are given below:

1. To examine the causality between dependent and independent variables.

2. To determine the short and long run connection among dependent variable and independent variables applying ARDL.

Next, we will develop the econometric strategy to estimate the connection among agriculture investment and gross domestic product growth in North Macedonia. To find this relationship between time series variables we will check whether the variables are stationary or non-stationary. After the confirmation of stationary, the next step is to check the co-integration between variables by estimating the ARDL Bound test.

The first quantitative plan of this study is the determination of the unit root of all dependent and independent variables applying the Augmented Dicky-Fuller unit root test. To apply co-integration analysis all selected variables must be integrated at level $\mathrm{I}(0)$ and first difference I (1). The ADF root test is used to test the fixed structures of long-term relationships for a variety of time series.

The equation of first order autoregressive process is given below:

$\Delta \mathrm{Y}_{t}=\delta_{o}+\delta \mathrm{Y}_{t-1}+\delta_{t}+\varepsilon_{t}$

In equation $1, \mathrm{Y}_{t}$ is the dependent variables, $\delta_{o}$ is the constant, and $\delta_{t}$ is the trend. So, the equation included both constant and trend.

We can draw the ADF equation for higher order

$Y_{t}=\delta_{o}+\delta_{1} \mathrm{Y}_{t-1}+\delta_{1} \mathrm{Y}_{t-2}+\ldots+\delta \mathrm{Y}_{t-p+2}+$
$\delta_{p-1} \mathrm{Y}_{t-p+1}+\delta_{p} \mathrm{Y}_{t-p}+\omega_{t}$

To simplify equation 2 , we added and subtracted the term $\delta_{p} y_{t-p+1}$

$\mathrm{Y}_{t}=\delta_{o}+\delta_{1} \mathrm{Y}_{t-1}+\delta_{2} \mathrm{Y}_{t-2}+\ldots+\delta_{p-2} \mathrm{Y}_{t-p+2}+$

$\left(\delta_{p-1}+\delta_{p}\right) \mathrm{Y}_{t-p+1}-\delta_{p} \Delta \mathrm{Y}_{t-p+1}+\omega_{t}$

In next step, we added and subtracted the term $\left(v_{p-1}+\delta_{p}\right) \mathrm{Y}_{t-p+2}$ in equation (3) and we get

$\mathrm{Y}_{t}=\delta_{o}+\delta \mathrm{Y}_{t-1}+\delta \mathrm{Y}_{t-2}+\ldots-\left(\delta_{p-1}+\right.$

$\left.\delta_{p}\right) \mathrm{Y}_{t-p+2}-v_{p} \Delta \mathrm{Y}_{t-p+1}+\varepsilon_{t}$

After the more simplification of equation 4, we get the more compact form of $\mathrm{ADF}$ equation

$\Delta \mathrm{Y}_{t}=\delta_{o}+\beta \mathrm{Y}_{t-1}+\stackrel{i=2}{\sum} \eta i \Delta \mathrm{Y}_{t-i+1}+\varepsilon_{t}(5)$

In previous equation, $\beta=1-\stackrel{\substack{p=1 \\ \sum}}{\sum} \delta_{i}$ and $\eta_{i}=-\stackrel{\substack{j=1 \\ p}}{\sum} \lambda_{j}$

If the value of $\beta=0$, the equation 5 will be stationary on first difference I $(I)$.

The Granger causality process can be defined from equation 6 and 7. It's pairwise process, and two variables cause each other. The process is given below:

$$
\begin{aligned}
& Y=\psi_{1}+\stackrel{\substack{i=1 \\
n}}{\sum} \lambda_{i} X_{t-1}+\stackrel{\substack{j=1 \\
m}}{m} \gamma_{j} Y_{t-j}+\sum_{j=0}^{m} Z_{t-j}+\mu_{1 t} \\
& X=\psi_{2}+\stackrel{i=1}{\sum} \delta_{i} X_{t-1}+\stackrel{\substack{j=1 \\
\sum}}{m} \theta_{j} Y_{t-j}+\sum_{j=0}^{m} Z_{t-j}+\mu_{2 t}
\end{aligned}
$$

In equations (6) and (7), we assume that both $\mu_{1 t}$ and $\mu_{2 t}$ are white noise error terms and are uncorrelated with each other.

In equations 6 and 7, both variables "X" and "Y" are regressed on its own lag's terms. The equation for variable "Y" is given below:

$Y=\psi_{1}+\stackrel{\substack{j=1 \\ m}}{m} \lambda_{j} Y_{t-j}+\mu_{1 t}$

By moving forward, we will regress "Y" on its own lag and on the other variable "X" 


$$
Y=\psi_{1}+\stackrel{\substack{i=1 \\ n}}{\sum} \lambda_{i} X_{t-i} \stackrel{\substack{m=1 \\ \sum}}{\sum} \gamma_{j} Y_{t-j}+\mu_{1 t}
$$

The next stage is to make a decision on the basis of null and alternative hypothesis. The null and alternative hypothesis are given below:

$H_{o}: \alpha_{1}=0$ or $\mathrm{X}$ does not cause $\mathrm{Y}$

$H_{1}: \alpha_{1} \neq 0$ or $\mathrm{X}$ does cause $\mathrm{Y}$

We will make the decision based on F-statistics value and the F-statistics formula is given below:

$$
F=\frac{\left(R S S_{R}-R S S_{U} / m\right.}{R S S_{U} /(n-k)}
$$

The $H_{o}$ hypothesis will be rejected and accepted the alternative if the F-statistics calculated value is greater than "F-critical value", then which is $\mathrm{X}$ does cause $\mathrm{Y}$.

The ARDL model for dependent and independent variables is given below:

$\mathrm{Y}_{t}=\mu+\sum_{i=1}^{n} \theta_{i} \mathrm{Y}_{t-i}+\sum_{i=0}^{n} \lambda_{1} X_{t-i}+v_{t}$

The higher order equation ARDL can be seen from equation 11.

$\mathrm{Y}_{t}=\mu+\theta_{i} \mathrm{Y}_{t-i}+\ldots+\theta_{n} \mathrm{Y}_{t-n}+\lambda_{o} X_{t}+$

$\lambda_{1} X_{t-1}+\ldots+\lambda_{y} X_{t-m}+\varpi_{t}$

In the above equation, both terms $Y_{t}$ and $X_{t}$ achieve to steady state level $Y^{*}$ and $X^{*}$ at constant rate.

$\mathrm{Y}^{*}=\lambda_{o}+\lambda_{1} X^{*}$

In the above equation 12 , the terms $Y^{*}$ and $X^{*}$ which indicate the long run relationship between dependent and independent variables. The $X^{*}$ is assumed to be a constant

$X=X_{t}=X_{t-1}=\ldots=X_{t-m}$

We put (13) into equation (10) for the estimations of the long run parameters

$\mathrm{Y}^{*}=\frac{\kappa \mu}{1-\sum \theta_{i}}+\frac{\sum \lambda_{i}}{1-\sum \theta_{i}} X^{*}$

In the above equation, we assume $A_{o}=\frac{\kappa \mu}{1-\sum \theta_{i}}$ and

$$
\begin{gathered}
A_{1}=\frac{\sum \lambda_{i}}{1-\sum \theta_{i}} \\
Y^{*}=A_{o}+A_{1} X^{*}
\end{gathered}
$$

The specification of error term $e_{t}$ is given in equation 15

$e_{t}=\mathrm{Y}_{t}-\mathrm{Y}^{*}=\mathrm{Y}_{t}-A_{o}-A_{1} X_{t}$

The more compact form of the ARDL model is given in equation (16)

$\Delta \mathrm{Y}_{t}=\mu+\sum_{i=1}^{n-1} \theta_{i} \Delta Y_{t-i}+\sum_{i=0}^{m-1} \lambda_{1} \Delta X_{t-i}-$

$\kappa \hat{e}_{t-1}+\varepsilon_{t}$
In equation (16) " $\kappa$ " is the key coefficient, here " $\kappa$ " is the error correction coefficient and it is generally recognized as the correction coefficient. The " $k$ " demonstrates how much the value of the equilibrium error is fixed.

In equation 17, we introduce all the dependent and independent variables.

$\Delta \mathrm{GDPG}_{t}=$

$\kappa_{0}+\sum_{i=1}^{n} \delta_{1} G D P G_{t-i}+\sum_{i=1}^{n} \delta_{2} A G R F F_{t-i}+$

$\sum_{i=1}^{n} \delta_{3} A G R L_{t-i}+\sum_{i=1}^{n} \delta_{4} A G E M S_{t-i}+$

$+\sum_{i=1}^{n} \delta_{5}$ AGRIM $_{t-i}+\sum_{i=1}^{n} \delta_{6} I N F L+\varepsilon_{t}$

In the above equation, the dependent variable is the growth of gross domestic product (GDPG) and the independent variables are agriculture, forestry, and fishing, value added (AGRFF), agricultural land which is the percentage of total land area in North Macedonia (AGRL), Agricultural methane emissions which is the percentage of total emission (AGEMS), Agricultural raw materials imports counted as the percentage of total merchandise imports in North Macedonia, (AGRIM), annual inflation rate (INFL).

\section{Results and Discussion}

We collected the data for a period of 1991 to 2020 and all the data is collected from World Development Indicator (World Bank). The average growth of the gross domestic product in North Macedonia between the years $1991-2020$ is 1.6306 percent. The biggest increase in GDP growth is seen in the year 2007 and the value was 6.4735 (Table 1.). On the other hand, the lowest value of GDP growth was -7.4692 in the year 1993. The maximum value of AGRFF is 22.4859 and the minimum noted value is -25.2024 . GDPG and AGRFF data is negatively skewed which means the data tail is more skewed on the left side of the bell shape curve. The average inflation rate in North Macedonia is 14.1045. In 1992 the value was on the highest level (134.7702) and the lowest value is recorded in the year of 1999 .

Table 1. Summary Statistics

\begin{tabular}{|l|c|c|c|c|c|c|}
\hline & GDPG & AGRFF & AGRL & AGEMS & AGRIM & INFL \\
\hline Mean & 1.630587 & -1.170352 & 49.01721 & 50.21924 & 1.821572 & 14.10454 \\
\hline Median & 2.874103 & 0.956349 & 50.14869 & 47.44618 & 1.263620 & 1.880867 \\
\hline Maximum & 6.473487 & 22.48585 & 52.45773 & 64.23640 & 4.688080 & 134.7702 \\
\hline Minimum & -7.469271 & -25.20240 & 40.16653 & 43.88894 & 0.726912 & -1.279287 \\
\hline Std. Dev. & 3.611188 & 10.83093 & 3.089724 & 5.885886 & 1.185110 & 35.01550 \\
\hline Skewness & -1.173713 & -0.240435 & -1.581863 & 1.122682 & 0.997281 & 2.800359 \\
\hline Kurtosis & 3.599968 & 3.007874 & 4.457767 & 2.714778 & 2.584001 & 9.316672 \\
\hline Jarque-Bera & 7.337965 & 0.289123 & 15.16781 & 6.403768 & 5.189171 & 89.08549 \\
\hline Probability & 0.025502 & 0.865402 & 0.000509 & 0.040685 & 0.074677 & 0.000000 \\
\hline Sum & 48.91762 & -35.11055 & 1470.516 & 1506.577 & 54.64717 & 423.1363 \\
\hline Sum Sq. Dev. & 378.1796 & 3401.962 & 276.8454 & 1004.666 & 40.73010 & 35556.47 \\
\hline Observations & 30 & 30 & 30 & 30 & 30 & 30 \\
\hline
\end{tabular}


The relationship between GDPG and AGRFF is positive and insignificant (Table 2.). A low correlation value indicates that the relationship between both variables is weak. The variable GDPG has a negative but significant association with the agricultural land in North Macedonia. The GDPG has a negative and significant relationship with all remaining variables. However, the AGRFF has a positive and insignificant correlation with all variables except the AGRL. Inflation is negatively correlated with the GDPG, but the relationship is significant. Therefore, we found that most of the variables are positively correlated with each other.

Table 2. Correlation Analysis

\begin{tabular}{|c|c|c|c|c|c|c|}
\hline Probability & GDPG & AGRFF & AGRL & AGEMS & AGRIM & INFL \\
\hline GDPG & 1.000000 & & & & & \\
\hline AGRFF & $\begin{array}{l}0.086911 \\
(0.6479)\end{array}$ & $\begin{array}{c}1.000000 \\
\cdots-\cdots\end{array}$ & & & & \\
\hline AGRL & $\begin{array}{c}-0.350914 \\
(0.0573)\end{array}$ & $\begin{array}{c}-0.148644 \\
(0.4331)\end{array}$ & $\begin{array}{c}1.000000 \\
\ldots\end{array}$ & & & \\
\hline AGEMS & $\begin{array}{c}-0.731484 \\
(0.0000)\end{array}$ & $\begin{array}{c}0.109111 \\
(0.5660)\end{array}$ & $\begin{array}{l}0.513790 \\
(0.0037)\end{array}$ & $\begin{array}{c}1.000000 \\
\ldots-\end{array}$ & & \\
\hline AGRIM & $\begin{array}{c}-0.642458 \\
(0.0001)\end{array}$ & $\begin{array}{l}0.221635 \\
(0.2392)\end{array}$ & $\begin{array}{c}0.416202 \\
(0.0222)\end{array}$ & $\begin{array}{l}0.908532 \\
(0.0000)\end{array}$ & $\begin{array}{c}1.000000 \\
\cdots\end{array}$ & \\
\hline INFL & $\begin{array}{c}-0.631398 \\
(0.0002)\end{array}$ & $\begin{array}{l}0.237991 \\
(0.2054)\end{array}$ & $\begin{array}{l}0.266153 \\
(0.1551)\end{array}$ & $\begin{array}{l}0.673352 \\
(0.0000)\end{array}$ & $\begin{array}{l}0.554240 \\
(0.0015)\end{array}$ & $\begin{array}{c}1.0000 \\
-\cdots-.\end{array}$ \\
\hline
\end{tabular}

According to Hill et.al (2001), time series variables must have unit roots to reduce the risk of spurious regression. Therefore, the first thing before checking whether co-integration occurs or not is the unit test to be checked. As we discussed earlier in methodology, we ran an ADF test to check data stationarity (Table 2.).

Table 3. Unit Root Test

\begin{tabular}{|c|c|c|c|c|}
\hline \multicolumn{2}{|c|}{$\mathbf{H}_{0}$ : Series is stationary } \\
\hline & \multicolumn{2}{|c|}{$\mathbf{I}(\mathbf{0})$} & \multicolumn{2}{c|}{ I (1) } \\
\hline & $\begin{array}{c}\text { With } \\
\text { Trend } \\
\text { and } \\
\text { Intercept }\end{array}$ & Prob. & $\begin{array}{c}\text { With } \\
\text { Trend } \\
\text { and } \\
\text { Intercept }\end{array}$ & Prob. \\
\hline GDPG & -2.9051 & 0.1755 & -6.7982 & $0.0000^{* * *}$ \\
\hline AGRFF & -4.1611 & $0.0140 * *$ & -7.2879 & $0.0000^{* * *}$ \\
\hline AGRL & -1.7386 & 0.7078 & -5.3297 & $0.0009^{* * *}$ \\
\hline AGEMS & -1.1676 & 0.8986 & -4.2313 & $0.0123^{* *}$ \\
\hline AGRIM & -7.1075 & $0.0001 * * *$ & -4.5991 & $0.0055^{* * *}$ \\
\hline INFL & -4.4106 & $0.0079^{* * *}$ & -7.2303 & $0.0000^{* * *}$ \\
\hline Note: 1\%, 5\% and 10\% represent the ****** and * significance level. \\
\hline \multicolumn{5}{|l|}{} \\
\hline
\end{tabular}

We noticed that few variables GDPG, AGRL, and AGEMS are stationary on both levels I (0) and the first difference I (1). The remaining variables have a unit root only on I (1). Thus, variables have a unit root of the combination of both I (0) and I (1) and this confirms we can run the ARDL model.
Table 4. Granger Causality Results

\begin{tabular}{|l|c|c|c|}
\hline Null Hypothesis: & Obs & F-Statistic & Prob. \\
\hline $\begin{array}{l}\text { AGRFF does not } \\
\text { Granger Cause GDPG }\end{array}$ & 29 & 5.82832 & $0.0231 * *$ \\
\hline $\begin{array}{l}\text { GDPG does not Granger Cause } \\
\text { AGRFF }\end{array}$ & 0.13830 & 0.7130 \\
\hline $\begin{array}{l}\text { INFL does not Granger } \\
\text { Cause GDPG }\end{array}$ & 29 & 9.47927 & $0.0049 * * *$ \\
\hline $\begin{array}{l}\text { GDPG does not Granger Cause } \\
\text { INFL }\end{array}$ & 15.3925 & $0.0006 * * *$ \\
\hline
\end{tabular}

According to bond co-integration test all variables are co-integrated on all significant levels $(\alpha=$ $1 \%, 2.5 \%, 5 \%, 10 \%$ ) (Table 4.). Because the Fstatistics value is greater than both lower I (0) and upper I (1) limits. Therefore, we concluded that cointegration exists between variables. Next, we will estimate both long and short run coefficients.

The AGRFF is positively and significantly correlated with growth of gross domestic product at $10 \%$ significant level (Table 5.).

Table 5. Long-run ARDL Coefficients (1, 0, 1, 1, 0, 1)

\begin{tabular}{|c|c|c|c|c|}
\hline Variable & $\begin{array}{c}\text { Coefficie } \\
\text { nt }\end{array}$ & Std. Error & t-Statistic & Prob. \\
\hline AGRFF & 0.084554 & 0.042820 & 1.974634 & $0.0630^{*}$ \\
\hline AGRL & 0.069516 & 0.143421 & -0.484698 & 0.6334 \\
\hline AGEMS & -0.394341 & 0.249805 & 1.578596 & 0.1309 \\
\hline AGRIM & 0.185083 & 0.900949 & -2.425313 & $0.0254^{* *}$ \\
\hline INFL & -0.101238 & 0.021988 & -4.604237 & $0.0002^{* * *}$ \\
\hline C & -9.365617 & 11.35446 & -0.824840 & 0.4197 \\
\hline Note: 1\%, 5\% and 10\% represent the ***, ** and * nignificance level. \\
\hline
\end{tabular}

If AGRFF increases one percent, the growth of gross domestic product will be increased by 8.45 percent. The next two variables AGRL and AGEMS are statistically insignificantly linked with the growth of the GDP. The relationship between agricultural methane emissions and the growth of gross domestic product. It indicates that the increase of the agriculture production will also increase the methane emission, and this has a positive relationship with economic growth. The inflation has a negative and statistically negative relationship with economic growth. It means the increase in commodity prices will decrease aggregate demand which will have a negative impact on country economic growth. Moreover, if inflation increases by one percent the value of economic growth will be decreases by $5.33 \%$.

The short-run ARDL results are given in Table 6. The variable AGRFF is positively and significantly correlated with the growth of the GDP in the short run. The AGRL has negative relationship with the growth of the GDP but the first lag is negatively correlated with GDPG. The value of inflation and its lag has a negative impact on the GDPG. 
Table 6. Short-run ARDL Coefficients (1, 0, 1, 1, 0, 1)

\begin{tabular}{|c|c|c|c|c|}
\hline Variable & Coefficient & Std. Error & t-Statistic & Prob.* \\
\hline GDPG(-1) & $\mid-0.084008$ & 0.227542 & -0.369197 & 0.7161 \\
\hline AGRFF & 0.091658 & 0.041551 & 2.205886 & $0.0399^{* *}$ \\
\hline AGRL & -0.339380 & 0.256942 & -1.320843 & 0.2022 \\
\hline AGRL (-1) & 0.264025 & 0.220415 & & 0.2457 \\
\hline AGEMS & -0.204789 & 570 & & \\
\hline AGEMS(-1) & 0.632257 & 43 & 1.740114 & $0.0980^{*}$ \\
\hline AGRIM & -2.30 & 0.916 & -2.583416 & $0.0182^{* *}$ \\
\hline INFL & -0.0 & & -2.9 & $0.0081 * *$ \\
\hline INFL(-1) & -0.0 & & & $0.0025^{* * *}$ \\
\hline $\mathrm{C}$ & 5240 & 11. & -0. & 0.3764 \\
\hline COINTEQ $(-1)^{*}$ & -0.643056 & 0.135324 & -4.751975 & $0.0001 * * *$ \\
\hline \multicolumn{5}{|c|}{ Diagnostic Results } \\
\hline & 0.793870 & \multirow{2}{*}{\multicolumn{2}{|c|}{$\begin{array}{l}\text { Adjusted R-squared } \\
\text { Durbin-Watson stat }\end{array}$}} & 6229 \\
\hline F-statistic & 1.849271 & & & 1.932990 \\
\hline $\begin{array}{l}\text { Prob(F- } \\
\text { statistic) }\end{array}$ & 0.000070 & \multicolumn{2}{|c|}{ Sum squared resid } & 64.97628 \\
\hline
\end{tabular}

The Durbin-Watson value is less than two which indicates the positive autocorrelation in residuals. The R-square explains the variation in dependent variable that explains the independent variables and, in our case, it is $79.39 \%$. The COINTEQ $(-1)$ value showing that the 64.31 percent error is corrected, and the value will converge towards equilibrium by $64.31 \%$ every year.

According to Granger causality results, we will reject the null hypothesis in which the AGRFF does not cause the GDPG because the probability value is less than 0.05 (Table 4.). In the case of the second statement, the GDPG does not cause the AGRFF because the probability value is greater than 0.05 . On the other hand, inflation does granger cause the GDPG and vice versa. Because the probability value is less than $\mathrm{a}=5 \%$ which means we will reject the null hypothesis.
The CUSUM for recurring residues and CUSUMSQ used for parameter strength tests Pesaran, 1997. The statistics collection test indicates a systematic change in the regression coefficients and the below figures showing the CUSUM and CUSUMSQ test results. The findings show the lack of any volatility coefficients because the CUSUM and CUSUM square statistics fall within the critical groups of $5 \%$ confidence intervals of parameter stability (Figures 1. and 2.). Therefore, there is a stabilization of the coefficients in the above sample time of North Macedonia.

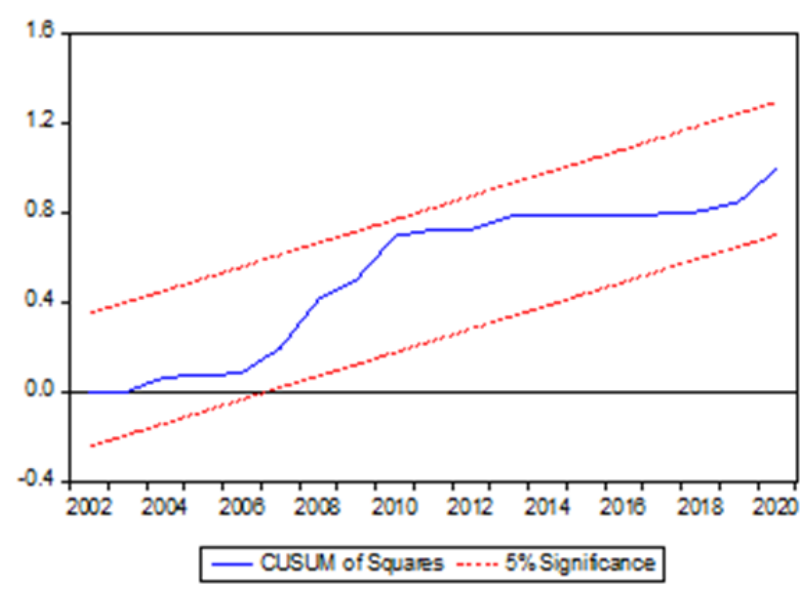

Figure 1.CUSUM of Squares

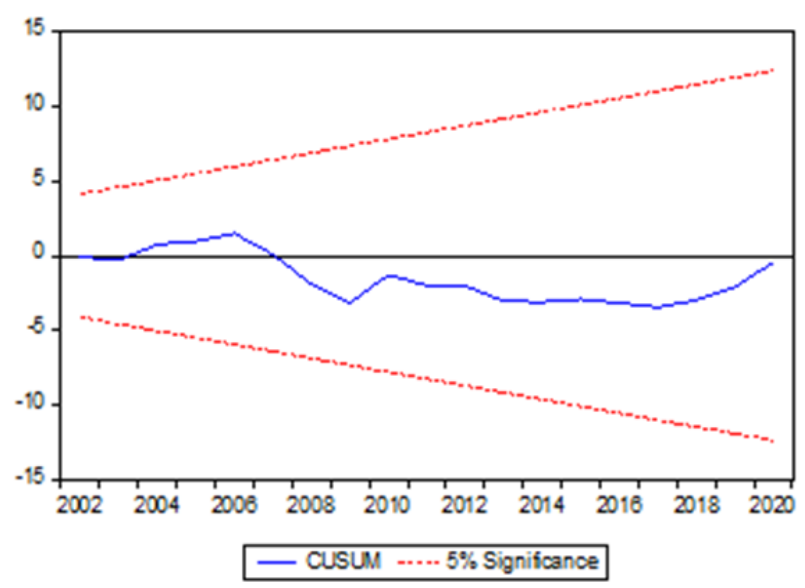

Figure 2. CUSUM 


\section{Conclusion}

We found a positive and significant relationship between agriculture, forestry, and fishing, valueadded, and the growth of the GDP in both the shortrun and the long run. Agricultural land is negatively correlated with the growth of the gross domestic product in the short run, but it has a positive relationship in the long run. The negative relationship in the short-run is because the economy can face a negative shock in the short-run e.g., due to natural disaster. Moreover, we found that the agricultural methane emissions which are emitted because of agriculture production have a negative impact on the GDP in both the short-term and the long-term. We noticed the agricultural raw materials imports have a negative impact on North Macedonia's GDP in the the short-term but both variables have a positive relationship in the long-term. We found the inflation has a negative impact on North Macedonia's GDP. In terms of related participation, agricultural production can have a significant impact on gross domestic product formation and become an accelerator for economic development. Considering the percentage created an additional amount for agricultural production, with appropriate measures and modern agricultural improvement and better placement activities of agricultural products, the opportunity to achieve higher economic growth to increase.

\section{References}

[1]. Acharya, S. S. (1997). Agricultural price policy and development: some facts and emerging issues. Indian Journal of Agricultural Economics, 52(1), 1-47.

[2]. Awokuse, T. O. (2009). Does agriculture really matter for economic growth in developing countries? (No. 319-2016-9808).

[3]. Brewster, C., Roussaki, I., Kalatzis, N., Doolin, K., \& Ellis, K. (2017). IoT in agriculture: Designing a Europe-wide large-scale pilot. IEEE communications magazine, 55(9), 26-33.

[4]. Diao, X., Hazell, P., \& Thurlow, J. (2010). The role of agriculture in African development. World development, 38(10), 1375-1383.

[5]. Djambaska, E., \& Lozanoska, A. (2019). Importance of the agricultural sector for the economic development of the Republic of North Macedonia. Economic Development, Journal of the Institute of Economics-Skopje.

[6]. Khan, W., \& Ansari, S. A. (2018). Does agriculture matter for economic growth of Uttar Pradesh (India)?. Ekonomika regiona. 2018. T. 14, vipusk 3, 14(3), 1029-1037.

[7]. Kydd, J., Dorward*, A., Morrison, J., \& Cadisch, G. (2004). Agricultural development and pro-poor economic growth in sub-Saharan Africa: potential and policy. Oxford Development Studies, 32(1), 37-57.

[8]. Lanz, B., Dietz, S., \& Swanson, T. (2018). Global economic growth and agricultural land conversion under uncertain productivity improvements in agriculture. American Journal of Agricultural Economics, 100(2), 545-569.

[9]. Long, T. B., Blok, V., \& Coninx, I. (2016). Barriers to the adoption and diffusion of technological innovations for climate-smart agriculture in Europe: evidence from the Netherlands, France, Switzerland and Italy. Journal of cleaner production, 112, 9-21.

[10]. Mundlak, Y., Cavallo, D., \& Domenech, R. (1989). Agriculture and economic growth in Argentina, 1913-84 (Vol. 76). Intl Food Policy Res Inst.

[11]. Pedersen, S. M., \& Lind, K. M. (Eds.). (2017). Precision Agriculture: Technology and Economic Perspectives (pp. 52-53). Springer International Publishing.

[12]. Rahman, Z., \& Hossain, M. E. (2014). Role of agriculture in economic growth of Bangladesh: A VAR approach. Journal of Business, 7, 163-185.

[13]. Schultz, T. W. (1968). Economic growth and agriculture. McGraw-Hill, New York. 